\title{
Dual light and redox control of NIR luminescence with comple- mentary photochromic and organometallic antennae.
}

\author{
Hassan Al Sabea, ${ }^{\dagger}$ Lucie Norel, ${ }^{*}{ }^{\dagger}$ Olivier Galangau, ${ }^{\dagger}$ Hussein Hijazi, ${ }^{\dagger}$ Remi Métivier, ${ }^{\dagger}$ Thierry \\ Roisnel,$^{\dagger}$ Olivier Maury, ${ }^{\#}$ Christophe Bucher, ${ }^{\#}$ François Riobé, ${ }^{\#}$ and Stéphane Rigaut* ${ }^{\dagger}$ \\ ${ }^{\dagger}$ Univ Rennes, CNRS, ISCR (Institut des Sciences Chimiques de Rennes) - UMR 6226, F-35000 Rennes, France. \\ t UMR CNRS 8531-PPSM, ENS Paris-Saclay, Université Paris-Saclay, 94235 Cachan, France. \\ \# Univ. Lyon, CNRS, Ecole Normale Supérieure de Lyon, Laboratoire de Chimie UMR 518246 allée d'Italie, F-69007 \\ Lyon, France
}

Supporting Information Placeholder

\begin{abstract}
With the help of a judicious association between dithienylethene (DTE) units, an ytterbium ion and a ruthenium carbon-rich complex, we describe (i) the efficient (on/off) switching of pure NIR luminescence with a photochromic unit absorbing in the UV range, and (ii) the association of electrochemical and photochemical control of this NIR emission in a single system with non-destructive readout.
\end{abstract}

Molecule-based switching devices in which key physical properties can be modulated with an external stimulus are currently the focus of much attention, most notably to address the development of smart miniaturized devices. ${ }^{1-3}$

In the particular domain of luminescence, conventional molecular switches use electric input signals to turn on and off emission activities via redox reactions centred either on the emitter or on a remote unit (electrofluorochromism). ${ }^{4}$ Such properties are useful for various applications in analytical chemistry, biological sensing and the development of optical memories and displays. On the other hand, associating fluorescent dyes with photochromic units is an effective strategy to tune emission with spatially and temporally resolved light input. ${ }^{5-7}$ Among all photochromic molecules, dithienylethene derivatives (DTE) receive much attention due to their remarkable photo-isomerization efficiency and deactivation schemes generally triggered by energy transfer from the excited state of the fluorophore (donor) to the photochromic unit (acceptor) in its conjugated state. ${ }^{5-6,8-10}$ Among all luminescence processes, the long-lived, narrow bandwidth NIR emission of lanthanide ions $\left(\mathrm{Nd}^{3+}, \mathrm{Yb}^{3+}\right.$ or $\left.\mathrm{Er}^{3+}\right)$ is well suited to the development of highly sensitive signaling tools due to its non-invasive nature and fast response time. ${ }^{11-14}$ Achieving a reversible modulation of pure NIR emission of lanthanides stands as a major objective both for the academic and industrial sectors. Surprisingly, this has been scarcely explored, as most research efforts have been focused on systems displaying larger emission band overlapping the visible range. ${ }^{15-17}$

Concerning electromodulation, few groups have successfully modulated NIR emission of $\mathrm{Yb}^{3+}$ and/or $\mathrm{Nd}^{3+}$ sensitized with redox active species. ${ }^{18-21}$ Some of us used a series of ruthenium acetylide complexes displaying strong ligand-mediated electronic effects ${ }^{22}$ that allowed the realization of several redox controlled optical switches or molecular devices. ${ }^{19,23-28}$ As far as photomodulation is concerned, whereas europium luminescence has been modulated with several photochromic units, ${ }^{29-33}$ we recently report the first attempt to modulate $\mathrm{Yb}(\mathrm{III})$ ion emission in the NIR range thanks to a DTE functionalized ligand used as a sensitizer in its closed form. However, the resulting emission was very weak. ${ }^{34}$

In this context, challenging goals remain to be reached to ensure the development of materials featuring controllable NIR properties. It includes (i) the achievement of efficient photo-control of bright NIR luminescence, and (ii) the combination of electro- and photomodulations in a single system to reach multi-functionality. ${ }^{35}$
Herein, we describe both accomplishments with the dual electrochemical and photochemical control of ytterbium luminescence by taking advantage of (i) the redox switching of the carbon-rich ruthenium antenna linked to the $\mathrm{Yb}$ (III) ion, and (ii) the photo-stimulation of three photochromic DTE units connected to the $\mathrm{Yb}$ (III) center with a $\beta$-diketonate moiety. This system stands also as a remarkable example enabling a non-destructive readout of photocontrollable luminescence. ${ }^{10}$

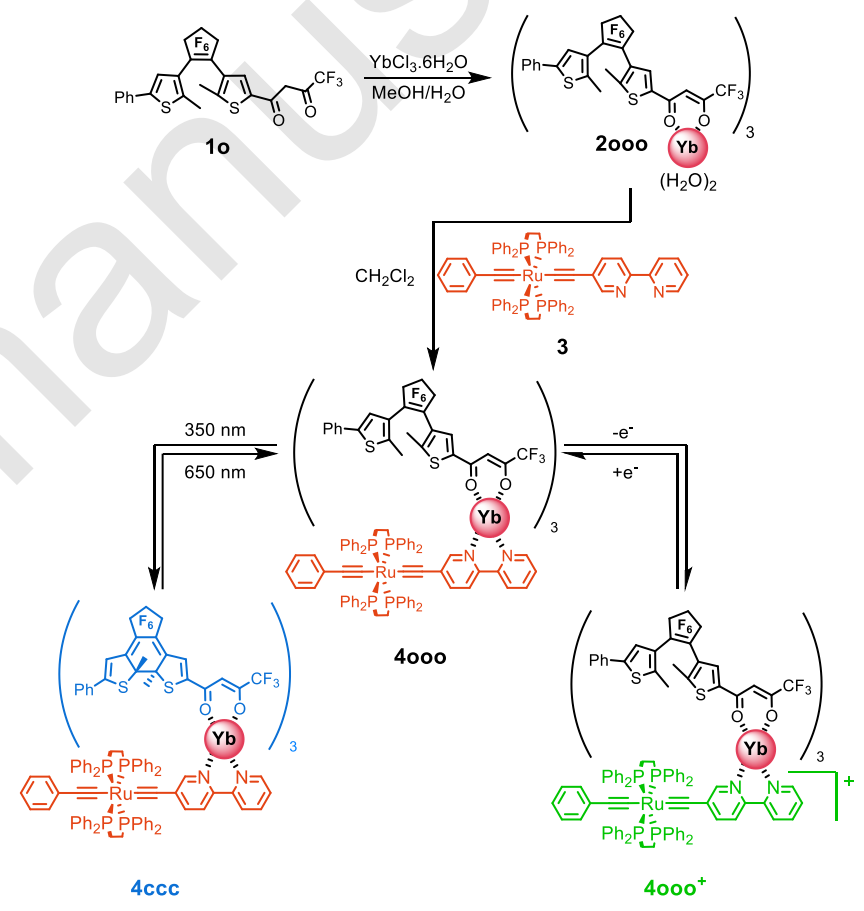

Scheme 1. Synthetic pathway to $\mathbf{4 0 0 0}$ and redox/optical commutation to $\mathbf{4 0 o o}^{+}$and 4 cce.

The DTE-modified precursor 10 was obtained in two steps from the known hydrogen terminated analogue lacking the $\beta$-diketonate function (Supplementary Information). Then, complexation of $\mathrm{Yb}$ (III) ion with three equivalents of $\mathbf{1 0}$ afforded the bis-aqua complex $\left[\mathrm{Yb}(\mathbf{1 0})_{3}\left(\mathrm{H}_{2} \mathrm{O}\right)_{2}\right]$ (20oo). Further displacement of the water molecules with the ruthenium-bipyridine ligand $\mathbf{3}$ led to complex 40oo, in good yield (85\%). This new compound was fully characterized with ${ }^{1} \mathrm{H}$ NMR and IR spectroscopies, and HR-MS. Good quality crystals suitable for X-ray structure determination were obtained from a $\mathrm{CH}_{2} \mathrm{Cl}_{2} / \mathrm{n}$-pentane biphasic mixture. 4000 crystallizes in the $P-1$ space group (Figure 1). This complex is rather large and some disorder on the DTE units lead to low quality refinement. However, the model is of sufficient quality to allow confirmation of the structure and bond lengths and angles are consistent with those measured on the analogue complex $\left[\operatorname{Ln}(3)(\mathrm{TTA})_{3}\right](\mathrm{Ln}=\mathrm{Eu}$, 
$\mathrm{Nd}$ ), the $\mathrm{Ln}^{3+}$ ion being in a slightly distorted square antiprismatic coordination polyhedron (supporting information). ${ }^{19}$

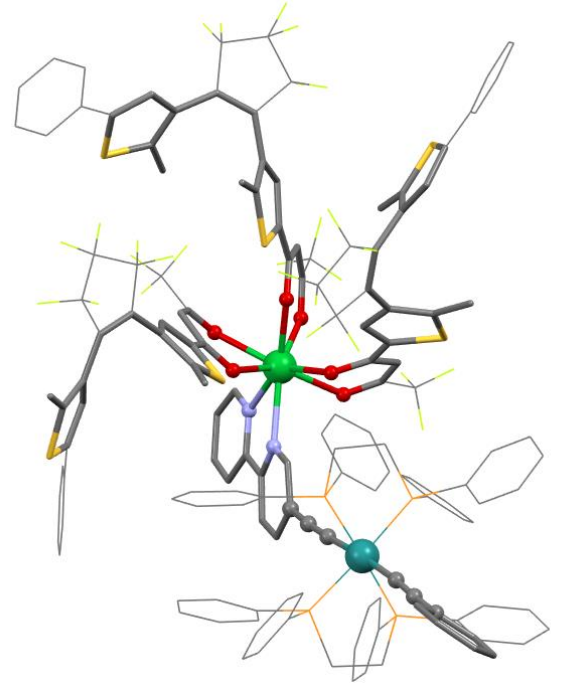

Figure 1. Simplified view of the crystal structure of $\mathbf{4 0 0 0}$ (H atoms have been omitted).

The absorption spectrum of $\mathbf{4 0 0 0}$ is similar to that of $\left[\mathrm{Yb}(\mathbf{3})(\mathrm{TTA})_{3}\right]^{18}$, with three main absorption bands observed at $\lambda_{\max }=272,343$ and $460 \mathrm{~nm}$ (Figure 2). The second transition is assigned to a DTE- $\beta$-diketonate ligand-centered absorption overlapping with $\pi-\pi^{*}$ transitions centered on the bipyridyl unit. The lower energy transition at $460 \mathrm{~nm}$ is a characteristic of the ruthenium acetylide moiety resulting from a Metal to Ligand Charge Transfer (MLCT)-type process from $\mathrm{Ru}(\mathrm{d} \pi) /$ alkynyl based orbitals to a $\pi^{*}$ orbital associated to the bipyridine unit. Note that $\mathbf{4 0 0 0}$ is found to be stable in solution, even in very diluted conditions $\left(10^{-}\right.$ $\left.5-10^{-6} \mathrm{~mol} . \mathrm{L}^{-1}\right)$, as proved by the absence of a band centred at 400 $\mathrm{nm}$ for the ruthenium-based free ligand 3. Upon irradiation of $\mathbf{4 0 0 0}$ at $\lambda_{\text {irr }}=350 \mathrm{~nm}$, a broad absorption assigned to the formation of the closed DTE ligand appears at $\lambda_{\max }=627 \mathrm{~nm}$. The solution can be further bleached back to the pure open form under visible irradiation $\left(\lambda_{\text {irr }}=650 \mathrm{~nm}\right)$, as attested by the quantitative recovering of the initial spectra. Importantly, irradiation of $\mathbf{4 0 0 0}$ at $\lambda=450 \mathrm{~nm}$ does not lead to any observable photochromic reaction. Further characterization of the photo conversion process could not be achieved with ${ }^{1} \mathrm{H}$ NMR spectroscopy due to the paramagnetic nature of the complexes that requires high NMR concentration and extended irradiation time inducing degradation. In order to identify the composition of the photostationnary state (PSS), the diamagnetic yttrium analogue 6000 was synthetized from the aqua complex $\left[\mathrm{Y}(\mathbf{1 0})_{3}\left(\mathrm{H}_{2} \mathrm{O}\right)_{2}\right](\mathbf{5 0 0 0})$. A similar synthesis was implemented from the PSS state (92\% conversion) of ligand 1c, the closed isomer of 1o, to achieve 6cce through to the aqua complex [Y $\left.(\mathbf{1 c})_{3}\left(\mathrm{H}_{2} \mathrm{O}\right)_{2}\right]$ (5ccc) (supplementary information). A careful integration of bipyridine-based ${ }^{1} \mathrm{H}$ NMR signals of $6 \mathbf{c c c}$ revealed in fact the presence of the 6occ and 6cce forms in $27 \%$ and $73 \%$, respectively (Figure S13), which is consistent with an initial composition of $92 \%$ in 1c. We also found that (i) the UV-vis spectra obtained after UV irradiation of 4000 and 6000 to their respective PSS states match exactly (Figure S14), and (ii) that they are identical to that recorded for 6ccc prepared chemically from 1c. These finding are thus consistent with the assumption that PSS after irradiation of $\mathbf{4 0 0 0}$ is composed of $27 \%$ of 4 occ and $73 \%$ of 4 ccc.
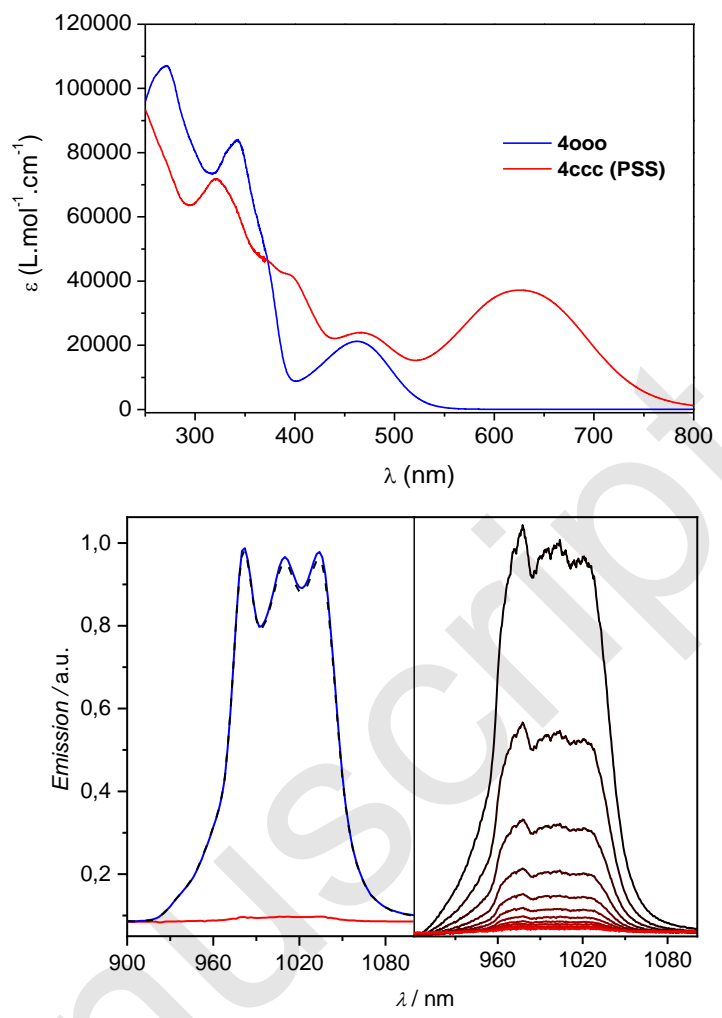

Figure 2. (up) Evolution of the absorption spectrum of 4000 upon UV irradiation $\left(\lambda_{\text {irr }}=350 \mathrm{~nm}\right)$ to PSS in $\mathrm{CH}_{2} \mathrm{Cl}_{2}$. The initial spectra were recovered after bleaching at $\lambda_{\text {irr }}=650 \mathrm{~nm}$. (down left) Initial emission spectrum of $\mathbf{4 0 0 0}$ in $\mathrm{CH}_{2} \mathrm{Cl}_{2}$ (blue), after UV irradiation $\left(\lambda_{\text {irr }}=350 \mathrm{~nm}\right.$, red $)$, and then bleaching $\left(\lambda_{\text {irr }}=650 \mathrm{~nm}\right.$, dashed $)$ with $\lambda_{\mathrm{ex}}=450 \mathrm{~nm}$. (down right) emission decay upon UV irradiation. Each spectrum is recorded with a $1 \mathrm{~s}$ time lapse

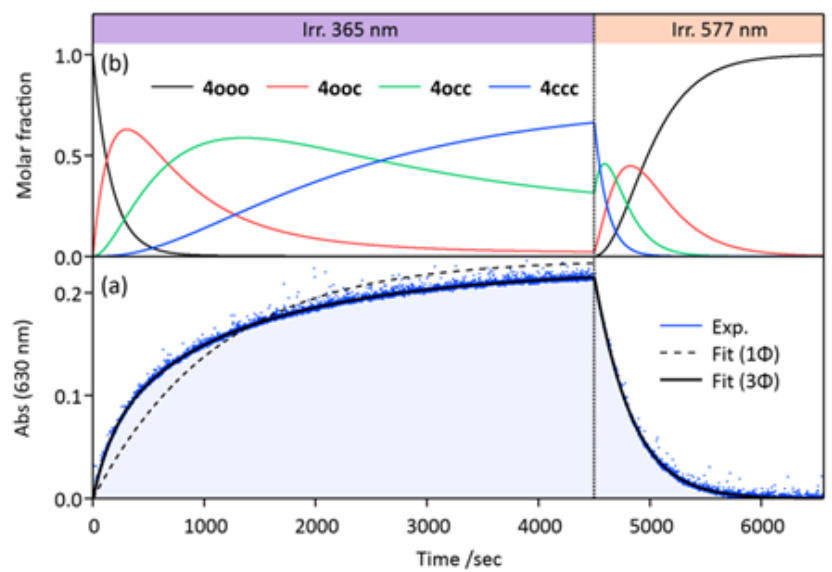

Figure 3. (a) Absorption time-profile recorded at $630 \mathrm{~nm}$ (blue dots) of a sample of $\mathbf{4 0 0 0}$ in $\mathrm{CH}_{2} \mathrm{Cl}_{2}$ under successive irradiation at $365 \mathrm{~nm}(380 \mu \mathrm{W})$ and $577 \mathrm{~nm}(8.8 \mathrm{~mW})$, and fitting curves involving a simple model (black dashed line: single $\Phi_{\mathrm{o} \rightarrow \mathrm{c}}$ ) and a complete model (black solid line: see text). (b) Molar fractions of the different species as a function of irradiation time (complete model).

Further photokinetic experiments were performed with irradiation of 4000 at $365 \mathrm{~nm}$. The absorption time-profile was analyzed numerically, based on the classical photochromic differential equations, to decipher the photochromic quantum yields (supporting information). ${ }^{36}$ When identical ring-closure quantum yields are con- 
sidered for the 3 successive closing reactions, calculated photokinetic curves cannot simulate the experimental profile (Figure 3a, black dashed line with $\left.\Phi_{0 \rightarrow c}=0.065\right)$. A model involving three different quantum yields of the sequential ring-closures $\mathbf{( 4 0 0 0} \rightarrow \mathbf{4 0 o c} \rightarrow \mathbf{4 0 c c} \rightarrow \mathbf{4 c c c})$ is necessary to fit appropriately the experimental data, with $\Phi_{\mathrm{ooo} \rightarrow \mathrm{ooc}}=0.16 \pm 0.01, \quad \Phi_{\mathrm{ooc} \rightarrow \mathrm{occ}}=$ $0.06 \pm 0.01, \Phi_{\mathrm{occ} \rightarrow \mathrm{ccc}}=0.03 \pm 0.01$ (Figure $3 \mathrm{a}$, black solid line). The lower values of the second and third quantum yields highlight the specific behavior of this multi-DTE system: ${ }^{37}$ The electrocyclization reaction efficiency is decreased by a factor $2-3$ when one or two DTE units are converted to the closed form. The calculated molar fractions of all species (Figure $3 \mathrm{~b}$ ) are compatible with the NMR experiments, with $75 \%$ of $4 \mathbf{c c c}$ calculated at the PSS. The ring-opening reaction was analyzed by the same method with $\lambda_{\text {irr }}$ $=577 \mathrm{~nm}$, and a satisfying fit was obtained with identical values of quantum yields for all photocycloreversion reactions $\left(\Phi_{\mathrm{c} \rightarrow \mathrm{o}}=\right.$ $0.006 \pm 0.002$ ).

The photophysical properties of $\mathbf{4 0 0 0}$ were further studied (Figure 2 and supplementary information). Upon excitation in the aforementioned MLCT transition $\left(\lambda_{\mathrm{ex}}=450 \mathrm{~nm}\right)$, a stable line shape emission, characteristic of the ytterbium ${ }^{2} \mathrm{~F}_{5 / 2} \rightarrow{ }^{2} \mathrm{~F}_{7 / 2}$ transition is observed in the NIR spectral range at $\lambda_{\max }=980 \mathrm{~nm}$ evidencing the antenna character of the ruthenium moiety. Then, emission photoswitching experiments were carried out using absorption and emission spectroscopies as monitoring techniques. These experiments revealed (i) the vanishing (to $1.4 \%$ of initial maximum intensity) of the emission signal upon UV irradiation $\left(\lambda_{\text {irr }}=350 \mathrm{~nm}\right)$ leading to the PSS, and (ii) a total recovery of the emission up to its initial intensity after visible irradiation $\left(\lambda_{\text {irr }}=650 \mathrm{~nm}\right)$. To the best of our knowledge, this is the first example where "pure" NIR emission can be reversibly switch on and off upon stimulation of a photochromic system. We also demonstrate that excitation in the MLCT band at $450 \mathrm{~nm}$ provides an efficient non-destructive read out of the system state. Our design not only avoids deleterious energy transfers, ${ }^{5}$ it also stresses the relevance of organometallic complexes as photosensitizers as they allow to separate MLCT excitation, photo-isomerization and emission wavelengths. The photoswitching process has also been investigated under dynamic regime: when excitation is performed at the photocyclization wavelength $\left(\lambda_{\text {irr }}=350 \mathrm{~nm}\right)$ and using the DTE $\beta$-diketonate ligands or the bipyridine unit as sensitizers, a fast decrease of the NIR signal is observed (Figure 2 and supplementary information). At this stage, the quenching mechanism remains speculative. However, a possible hypotheses is that the closed DTE excited triplet state lies at lower energy than that of the ${ }^{2} \mathrm{~F}_{5 / 2}$ excited state of the $\mathrm{Yb}$ (III) ion $\left(10200 \mathrm{~cm}^{-1}\right){ }^{5}$

The switching properties of $\mathbf{4 0 0 0}$ have been further investigated using electrochemical methods coupled to either absorption or fluorescence spectroscopies. Initial cyclic voltammetry curves $\left(\mathrm{CH}_{2} \mathrm{Cl}_{2}, 0.2 \mathrm{M} \mathrm{Bu}_{4} \mathrm{NPF}_{6}\right)$ revealed the existence of a single reversible wave at $E_{1}{ }^{\circ}=0.049 \mathrm{~V} v s . \mathrm{FeCp}_{2} / \mathrm{FeCp}_{2}{ }^{+}(\Delta E \mathrm{p}=83 \mathrm{mV})$ ascribed to the one electron oxidation of the ruthenium acetylide subunit. Spectroelectrochemistry (SEC) measurements carried out in the UV/Vis/NIR range then showed that the one electron oxidation of 4000 leads to a gradual disappearance of the band centered at $\lambda_{\max }=460 \mathrm{~nm}$ at the expense of a new broad absorption band at $\lambda_{\max }=1060 \mathrm{~nm}\left(\varepsilon=9500 \mathrm{~mol}^{-1} \cdot \mathrm{L} \cdot \mathrm{cm}^{-1}\right)($ Figure S19).

In order to modulate the emission of $\mathbf{4 0 0 0}$ with an electric stimulation, our investigations were carried out in a home-made SEC quartz cell mounted in a fluorimeter, with recording the emission at $\lambda=1025 \mathrm{~nm}\left(\lambda_{\mathrm{ex}}=450 \mathrm{~nm}\right)$ when scanning the electrode potential $(20 \mathrm{mV} / \mathrm{s})$ of the platinum grid between $-0.1 \mathrm{~V}$ an $1 \mathrm{~V}$. The main findings are captured in Figure 4A/B, showing the changes in the emission intensity together with the cyclic voltammetry experiment implemented at the electrode. It results that the one electron oxidation of $\mathbf{4 0 0 0}$ is associated to a drastic drop in the emission intensity down to $12 \%$ of its original value $\left(t_{1} \rightarrow t_{3}\right.$ in Figure $4 A$ and $\left.4 B\right)$. Most importantly, we found that the initial emission intensity can be almost fully recovered $(93 \%)$ upon scanning the electrode potential back to the starting open circuit potential $E=-0.1 \mathrm{~V}\left(\mathrm{t}_{3} \rightarrow \mathrm{t}_{5}\right.$ in Figure 4A and 4B). The second oxidation cycle, shown as a dashed curve in Figure 4, led to a similar quenching down to $7 \%$ of the emission intensity. It should be mentioned that these quenching ratio stand among the very best reported so far for strategies involving electrochemical quenching of lanthanide emission. ${ }^{20-21}$, 38-40 The simultaneous recording of the current-potential and emission responses clearly demonstrate that the changes in emission are triggered by the reversible transformation of $\mathbf{4 0 0 0}$ into $\mathbf{4 0 0 0}^{+}$. As previously discussed, ${ }^{19}$ extinction of NIR emission with $\mathbf{4 0 o 0}^{+}$can be rationalized either by the oxidation of the ruthenium acetylide moieties preventing any sensitization through an electron transfer mechanism, or by the new transition at c.a. $1060 \mathrm{~nm}$ that can afford a preferential non-radiative back-energy transfer pathway from the ${ }^{2} \mathrm{~F}_{5 / 2}$ ytterbium excited state.

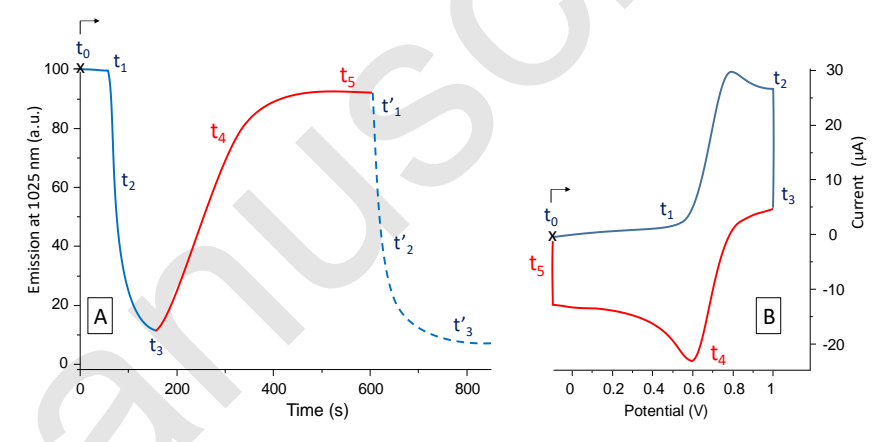

Figure 4. Emission monitoring at $\lambda=1025\left(\lambda_{\mathrm{ex}}=450 \mathrm{~nm}\right)$ upon oxidation (blue lines) and reduction (red lines) of $\mathbf{4 0 0 0}$ in the electrochemical cell, and simultaneously measured current-potential curve showing oxidation and reduction of $4000\left(\mathrm{E}^{\circ}=0.69 \mathrm{~V}\right.$ vs. Ag wire pseudo reference).

In conclusion, these results establish that (i) the possibility to switch pure NIR luminescence with a photochromic unit absorbing in the UV range, and (ii) that both electrochemical and photochemical control of luminescence can be efficiently achieved in a single system with non-destructive readout. Further studies, using spectroscopic and theoretical tools, will provide better insights in the understanding of this system as well as its extension to other lanthanide ions.

\section{ASSOCIATED CONTENT}

\section{Supporting Information}

The Supporting Information is available free of charge on the ACS Publications website. Synthetic procedures, cif file and spectroscopic data.

\section{AUTHOR INFORMATION}

\section{Corresponding Author}

lucie.norel@univ-rennes1.fr

stephane.rigaut@univ-rennes1.fr

\section{Notes}

The authors declare no competing financial interests. 


\section{ACKNOWLEDGMENT}

We thank the Universite de Rennes 1, the CNRS, the GDR MCM2 and the Agence Nationale de la Recherche (RuOxLux - ANR-12BS07-0010-01) for support.

\section{REFERENCES}

1. Feringa, B. L., Ed. Molecular Switches; Wiley-VCH: Weinheim, Germany, 2001.

2. Erbas-Cakmak, S.; Leigh, D. A.; McTernan, C. T.; Nussbaumer, A. L., Artificial Molecular Machines. Chem. Rev. 2015, 115, 10081-10206.

3. Kathan, M.; Hecht, S., Photoswitchable molecules as key ingredients to drive systems away from the global thermodynamic minimum. Chem. Soc. Rev. 2017, 46, 5536-5550.

4. Audebert, P.; Miomandre, F., Electrofluorochromism: from molecular systems to set-up and display. Chem. Sci. 2013, 4, 575-584.

5. Irie, M.; Fukaminato, T.; Matsuda, K.; Kobatake, S., Photochromism of Diarylethene Molecules and Crystals: Memories, Switches, and Actuators. Chem. Rev. 2014, 114 , 12174-12277.

6. Zhang, J.; Tian, H., The Endeavor of Diarylethenes: New Structures, High Performance, and Bright Future. Advanced Optical Materials 2018, 6, 1701278 .

7. Klaue, K.; Garmshausen, Y.; Hecht, S., Taking Photochromism beyond Visible: Direct One-Photon NIR Photoswitches Operating in the Biological Window. Angew. Chem. Int. Ed. 2018, 57, 1414-1417.

8. $\quad \mathrm{Su}$, J.; Fukaminato, T.; Placial, J.-P.; Onodera, T.; Suzuki, R.; Oikawa, H.; Brosseau, A.; Brisset, F.; Pansu, R.; Nakatani, K.; Métivier, R., Giant Amplification of Photoswitching by a Few Photons in Fluorescent Photochromic Organic Nanoparticles. Angew. Chem. Int. Ed. 2016, 55, 3662-3666.

9. Fernández-Acebes, A.; Lehn, J.-M., Optical Switching and Fluorescence Modulation in Photochromic Metal Complexes. Adv. Mater. 1998, 10, 1519-1522.

10. Irie, M.; Fukaminato, T.; Sasaki, T.; Tamai, N.; Kawai, T., A digital fluorescent molecular photoswitch. Nature 2002, 420, 759-760.

11. Bünzli, J.-C. G., Lanthanide Luminescence for Biomedical Analyses and Imaging. Chem. Rev. 2010, 110, 2729-2755.

12. dos Santos, C. M. G.; Harte, A. J.; Quinn, S. J.; Gunnlaugsson, T., Recent developments in the field of supramolecular lanthanide luminescent sensors and self-assemblies. Coord. Chem. Rev. 2008, 252, 2512-2527.

13. Moore, E. G.; Samuel, A. P. S.; Raymond, K. N., From Antenna to Assay: Lessons Learned in Lanthanide Luminescence. Acc. Chem. Res. 2009, 42, 542-552.

14. Pointillart, F.; Bourdolle, A.; Cauchy, T.; Maury, O.; Le Gal, Y.; Golhen, S.; Cador, O.; Ouahab, L., In Solution Sensitization of Er(III) Luminescence by the 4-Tetrathiafulvalene-2,6-pyridinedicarboxylic Acid Dimethyl Antenna Ligand. Inorg. Chem. 2012, 51, 978-984.

15. Bonacchi, S.; Cantelli, A.; Battistelli, G.; Guidetti, G.; Calvaresi, M.; Manzi, J.; Gabrielli, L.; Ramadori, F.; Gambarin, A.; Mancin, F.; Montalti, M., Photoswitchable NIR-Emitting Gold Nanoparticles. Angew. Chem. Int. Ed. 2016, 55, 11064-11068.

16. Jeong, K.; Park, S.; Lee, Y. D.; Lim, C. K.; Kim, J.; Chung, B. H.; Kwon, I. C.; Park, C. R.; Kim, S., Conjugated polymer/photochromophore binary nanococktails: bistable photoswitching of near-infrared fluorescence for in vivo imaging. Adv. Mater. 2013, 25, 5574-80.

17. Lim, H.; Seo, S.; Pascal, S.; Bellier, Q.; Rigaut, S.; Park, C.; Shin, H.; Maury, O.; Andraud, C.; Kim, E., NIR Electrofluorochromic Properties of Aza-Boron-dipyrromethene Dyes. Sci. Rep. 2016, 6, 18867 18867

18. Di Piazza, E.; Norel, L.; Costuas, K.; Bourdolle, A.; Maury, O.; Rigaut, S., d-f Heterobimetallic Association between Ytterbium and Ruthenium Carbon-Rich Complexes: Redox Commutation of Near-IR Luminescence. J. Am. Chem. Soc. 2011, 133, 6174-6176.

19. Norel, L.; Di Piazza, E.; Feng, M.; Vacher, A.; He, X. Y.; Roisnel, T.; Maury, O.; Rigaut, S., Lanthanide Sensitization with Ruthenium Carbon-Rich Complexes and Redox Commutation of Near-IR Luminescence. Organometallics 2014, 33, 4824-4835.

20. Tropiano, M.; Kilah, N. L.; Morten, M.; Rahman, H.; Davis, J. J.; Beer, P. D.; Faulkner, S., Reversible Luminescence Switching of a Redox-Active Ferrocene-Europium Dyad. J. Am. Chem. Soc. 2011, 133, 11847-11849.
21. Molloy, J. K.; Jarjayes, O.; Philouze, C.; Fedele, L.; Imbert, D. Thomas, F., A redox active switch for lanthanide luminescence in phenolate complexes. Chem. Commun. 2017, 53, 605-608.

22. Costuas, K.; Rigaut, S., Polynuclear carbon-rich organometallic complexes: clarification of the role of the bridging ligand in the redox properties. Dalton Trans. 2011, 40, 5643-5658.

23. Samoc, M.; Gauthier, N.; Cifuentes, M. P.; Paul, F.; Lapinte, C.; Humphrey, M. G., Electrochemical switching of the cubic nonlinear optical properties of an aryldiethynyl-linked heterobimetallic complex between three distinct states. Angew. Chem. Int. Ed. 2006, 45, 7376-7379.

24. Liu, Y. F.; Lagrost, C.; Costuas, K.; Tchouar, N.; Le Bozec, H.; Rigaut, S., A multifunctional organometallic switch with carbon-rich ruthenium and diarylethene units. Chem. Commun. 2008, 6117-6119.

25. Tanaka, Y.; Ishisaka, T.; Inagaki, A.; Koike, T.; Lapinte, C.; Akita, M., Photochromic Organometallics with a Dithienylethene (DTE) Bridge, $[\mathrm{Y}-\mathrm{C} \equiv \mathrm{C}-\mathrm{DTE}-\mathrm{C} \equiv \mathrm{C}-\mathrm{Y}]\left(\mathrm{Y}=\left\{\mathrm{MCp}^{*}(\mathrm{dppe})\right\}\right)$ : Photoswitchable Molecular Wire $(\mathrm{M}=\mathrm{Fe})$ versus Dual Photo- and Electrochromism ( $\mathrm{M}=\mathrm{Ru})$. Chem. Eur. J. 2010, 16, 4762-4776.

26. Meng, F. B.; Hervault, Y. M.; Shao, Q.; Hu, B. H.; Norel, L.; Rigaut, S.; Chen, X. D., Orthogonally modulated molecular transport junctions for resettable electronic logic gates. Nat. Commun. 2014, $5,9$.

27. Mulas, A.; He, X.; Hervault, Y.-M.; Norel, L.; Rigaut, S.; Lagrost, C., Dual-Responsive Molecular Switches Based on DithienyletheneRuII Organometallics in Self-Assembled Monolayers Operating at Low Voltage. Chem. Eur. J. 2017, 23, 10205-10214.

28. Qi, H.; Gupta, A.; Noll, B. C.; Snider, G. L.; Lu, Y.; Lent, C.; Fehlner, T. P., Dependence of Field Switched Ordered Arrays of Dinuclear Mixed-Valence Complexes on the Distance between the Redox Centers and the Size of the Counterions. J. Am. Chem. Soc. 2005, 127, 15218-15227.

29. Mei, J. F.; Lv, Z. P.; Lai, J. C.; Jia, X. Y.; Li, C. H.; Zuo, J. L.; You, X. Z., A novel photo-responsive europium(III) complex for advanced anti-counterfeiting and encryption. Dalton Trans. 2016, 45, 5451-5454.

30. Cheng, H.-B.; Zhang, H.-Y.; Liu, Y., Dual-Stimulus Luminescent Lanthanide Molecular Switch Based on an Unsymmetrical Diarylperfluorocyclopentene. J. Am. Chem. Soc. 2013, 135, 10190-10193.

31. Hasegawa, Y.; Nakagawa, T.; Kawai, T., Recent progress of luminescent metal complexes with photochromic units. Coord. Chem. Rev. 2010, 254, 2643-2651.

32. Cheng, H.-B.; Hu, G.-F.; Zhang, Z.-H.; Gao, L.; Gao, X.; Wu, H.-C., Photocontrolled Reversible Luminescent Lanthanide Molecular Switch Based on a Diarylethene-Europium Dyad. Inorg. Chem. 2016, 55 (16), 7962-7968.

33. Sun, J.-K.; Cai, L.-X.; Chen, Y.-J.; Li, Z.-H.; Zhang, J., Reversible luminescence switch in a photochromic metal-organic framework. Chem. Commun. 2011, 47, 6870-6872.

34. He, X.; Norel, L.; Hervault, Y.-M.; Métivier, R.; D’Aléo, A.; Maury, O.; Rigaut, S., Modulation of Eu(III) and Yb(III) Luminescence Using a DTE Photochromic Ligand. Inorg. Chem. 2016, 55, 12635-12643.

35. Zhu, W.; Song, L.; Yang, Y.; Tian, H., Novel Bisthienylethene Containing Ferrocenyl-Substituted Naphthalimide: A Photo- and Redox Multi-Addressable Molecular Switch. Chem. Eur. J. 2012, 18, 1338813394.

36. Nakatani, K.; Piard, J.; Yu,.P.; Métivier, R. in Photochromic materials: preparation, properties and applications, 1st Edition, Tian H., Zhang J., Eds.; Wiley-VCH, 2016, pp. 1-45.

37. Fihey, A.; Perrier, A.; Browne, W. R.; Jacquemin, D., Multiphotochromic molecular systems. Chem. Soc. Rev. 2015, 44, 3719-3759.

38. Yano, M.; Matsuhira, K.; Tatsumi, M.; Kashiwagi, Y.; Nakamoto, M.; Oyama, M.; Ohkubo, K.; Fukuzumi, S.; Misaki, H.; Tsukube, H., "ON-OFF" switching of europium complex luminescence coupled with a ligand redox process. Chem. Commun. 2012, 48, $4082-4084$.

39. Sato, T.; Higuchi, M., An alternately introduced heterometallosupramolecular polymer: synthesis and solid-state emission switching by electrochemical redox. Chem. Commun. 2013, 49, 5256-5258.

40. Kanazawa, K.; Nakamura, K.; Kobayashi, N., Electrochemical luminescence modulation in a Eu(III) complex-modified TiO2 electrode. $J$. Mater. Chem. C 2015, 3, 7135-7142. 


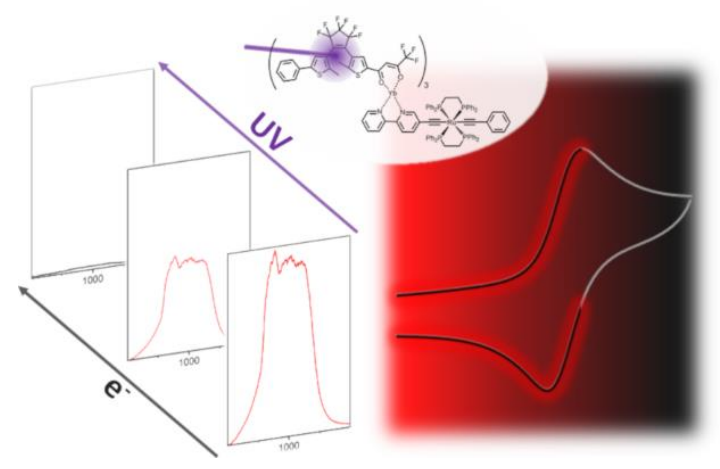

